\title{
Peri-Implant Mucosa Augmentation with an Acellular Collagen Matrix
}

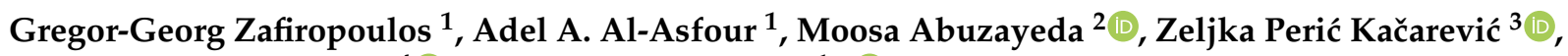 \\ Colin Alexander Murray ${ }^{4}$ (D) and Branko Trajkovski ${ }^{1, *(1)}$ \\ 1 Department of Surgical Sciences, Faculty of Dentistry, Kuwait University, 13110 Safat, Kuwait; \\ ggzafi@gmx.de (G.-G.Z.); adel.alasfour@ku.edu.kw (A.A.A.-A.) \\ 2 Department of Prosthodontics, College of Dentistry, MBR University, Dubai 505055, United Arab Emirates; \\ Moosa.Abuzayda@mbru.ac.ae \\ 3 Department of Anatomy Histology, Embryology, Pathology Anatomy and Pathology Histology, Faculty of \\ Dental Medicine and Health, University of Osijek, 31000 Osijek, Croatia; zeljkapericc@gmail.com \\ 4 Department of Preventive and Restorative Dentistry, College of Dental Medicine, University of Sharjah, \\ Sharjah 27272, United Arab Emirates; profcolinmurray@outlook.com \\ * Correspondence: biobranko@gmail.com
}

\section{check for} updates

Citation: Zafiropoulos, G.-G.; Al-Asfour, A.A.; Abuzayeda, M.; Kačarević, Z.P.; Murray, C.A.; Trajkovski, B. Peri-Implant Mucosa Augmentation with an Acellular Collagen Matrix. Membranes 2021, 11, 698. https://doi.org/10.3390/ membranes11090698

Academic Editors: Oliver Gorke, Mike Barbeck, Ole Jung, Stevo Najman and Xin Xiong

Received: 7 August 2021

Accepted: 9 September 2021

Published: 12 September 2021

Publisher's Note: MDPI stays neutral with regard to jurisdictional claims in published maps and institutional affiliations.

Copyright: (c) 2021 by the authors. Licensee MDPI, Basel, Switzerland. This article is an open access article distributed under the terms and conditions of the Creative Commons Attribution (CC BY) license (https:/ / creativecommons.org/licenses/by/ $4.0 /)$.

\begin{abstract}
Peri-implant keratinized mucosa (PI-KM) may support implant survival. Acellular collagen matrices (aCMs) have been widely used to facilitate soft tissue regeneration. The aim of this study was to investigate clinical outcomes obtained with the use of an aCM (mucoderm ${ }^{\circledR}$ ) to enhance PI-KM. In this retrospective non-randomized case series, 27 restored implants in 14 patients (eight males and six females, mean age $=56$ years) with a PI-KM width $\leq 1 \mathrm{~mm}$ were followed for 6 months. It was demonstrated that aCM grafts augmented PI-KM effectively (mean increase of $5.4 \mathrm{~mm} ;>533 \%$ ) without a significant change in bleeding on probing (BOP) from baseline. The mean aCM shrinkage was $3.9 \mathrm{~mm}(42 \%)$. Gender, area, arch, and BOP did not influence PI-KM augmentation or aCM shrinkage significantly. The present results demonstrated that the examined aCM was effective and predictable for attaining a band of keratinized tissue, while avoiding graft donor site harversting.
\end{abstract}

Keywords: collagen; dental implants; collagen matrix; soft tissue augmentation; keratinized mucosa

\section{Introduction}

The use of dental implants is an effective procedure to replace missing teeth, with implant survival rates up to $95 \%$ after 10 years of prosthetic loading [1,2]. There is ongoing debate regarding the importance of keratinized tissue width for maintenance of periodontal and prevention of soft tissue recession, with some recommending a minimum width of $2 \mathrm{~mm}$ for maintenance gingival health [3,4]. However, provided that traumatic tooth brushing and inflammation are controlled, patients have been reported to maintain gingival health without deterioration or progression of gingival recession with a minimal band of gingiva $[3,4]$. Thus, a narrow band of attached keratinized gingiva alone is not considered an absolute indication for gingival augmentation.

Nevertheless, implant sites with $<2 \mathrm{~mm}$ of keratinized mucosa $(\mathrm{KM})$ have been found to be prone to brushing discomfort, plaque accumulation, and peri-implant inflammation compared to implant sites with more keratinized tissue [5,6]. Implant failures can be classified as mechanical or biologic, with peri-implant diseases being considered as the most common causes of implant-related biologic complications [7]. Although peri-implant keratinized mucosa (PI-KM) has not been established as a prognostic factor for implant survival [8], the presence of PI-KM has been associated with implant-neck seal stability that facilitates cleaning and limiting bacterial infiltration into the rehabilitated region $[7,9]$. The width and thickness of PI-KM do not appear to compromise the mechanical stability of implants. However, they have been correlated negatively with peri-implant soft-tissue 
recession, plaque accumulation and inflammation [3]. Moreover, a narrow band of PI-KM together with a technical complication such as loosening of the abutment screw could lead to fistula formation and subsequent peri-implantitis and implant failure [8,10].

Given the common view of KM width as a keystone for the maintenance of periodontal and peri-implant health, free gingival graft (FGG) placement to increase KM width has become common [4,11-16]. However, areas augmented by FGGs are characterized by differences in texture and color from those of adjacent soft tissues. Furthermore, FGGs must be harvested from palatal donor sites, which entails postoperative morbidity and limited availability $[6,11-13,17]$. Collagen matrices (CMs) have been introduced as an alternative materials for soft-tissue augmentation, but few clinical studies have examined the use of CMs for PI-KM width augmentation [18-22]. In particular, there are not enough data to conclude whether CMs increase PI-KM width effectively in implant areas.

In the present study, an acellular collagen matrix $(\mathrm{aCM})$ was used as a grafting material to increase the PI-KM width and to avoid donor-site harvesting. Therefore, we conducted a retrospective analysis of 27 implant restorations in which the PI-KM was treated with the $\mathrm{aCM}$ during a 6 month observation period.

\section{Materials and Methods}

\subsection{Study Population}

In this retrospective non-randomized case series, 27 prosthetically restored implants in 14 patients (eight males and six females, mean age $=56$ years) were analyzed. In the target areas, only a small amount of PI-KM was observed. The patients were treated by one of the authors (GGZ) between 2012 and 2016. Only one area per patient (randomly selected if more than one) was included in the present analysis. The inclusion criteria were: (1) non-smoker; (2) good systemic and periodontal health; (3) PI-KM width $\leq 1 \mathrm{~mm}$ in target implant area (Figure 1A); (4) implant restorations loaded $\geq 3$ months prior to the present treatment; (5) already enrolled in a supportive periodontal care program consisting of three follow-up appointments per year, demonstrating good oral hygiene and compliance (full mouth plaque score $\leq 12 \%$ ); and (6) willingness and ability to provide informed consent.

\subsection{Surgical Treatment and Clinical Measurements}

Alveolar mucosa was stained with Schiller iodine solution to facilitate mucogingival junction identification. Local anesthesia was achieved with $4 \%$ articaine $\mathrm{HCl}$ injection containing 1:100,000 epinephrine (Ultracain D-S forte; Sanofi-Aventis, Frankfurt/M, Germany). A horizontal mucosal incision was made in the mucogingival junction with a \#15 surgical blade and extended for $3 \mathrm{~mm}$ from the mesial level of the first implant and distal to the last implant. A partial thickness mucosal flap was prepared, displaced apically, and sutured at the base of the newly created vestibule with 5-0 non-resorbable sutures (Ethibon; Ethicon-Johnson \& Johnson, Cincinnati, OH). Coronal PI-KM was not removed or retracted (Figure 1B).

A three-dimensional $1.7 \mathrm{~mm}$-thick porcine derived aCM (mucoderm ${ }^{\circledR} ; 30 \times 40 \mathrm{~mm}^{2}$ or $15 \times 20 \mathrm{~mm}^{2}$; EC 0483; botiss biomaterials, Zossen, Germany) was used for soft tissue augmentation. The aCM was hydrated in sterile saline solution for $10 \mathrm{~min}$, trimmed, positioned in the vestibule, and fixated on the periosteum with interrupted simple-loop resorbable sutures (5-0 Monocryl; Johnson \& Johnson Int., Neuss, Germany). The fixated $\mathrm{aCM}$ was left exposed, and moist gauze was applied to the grafted site with light finger pressure for $5 \mathrm{~min}$ to minimize blood clot formation between the $\mathrm{aCM}$ and surrounding tissues (Figure 1B). 

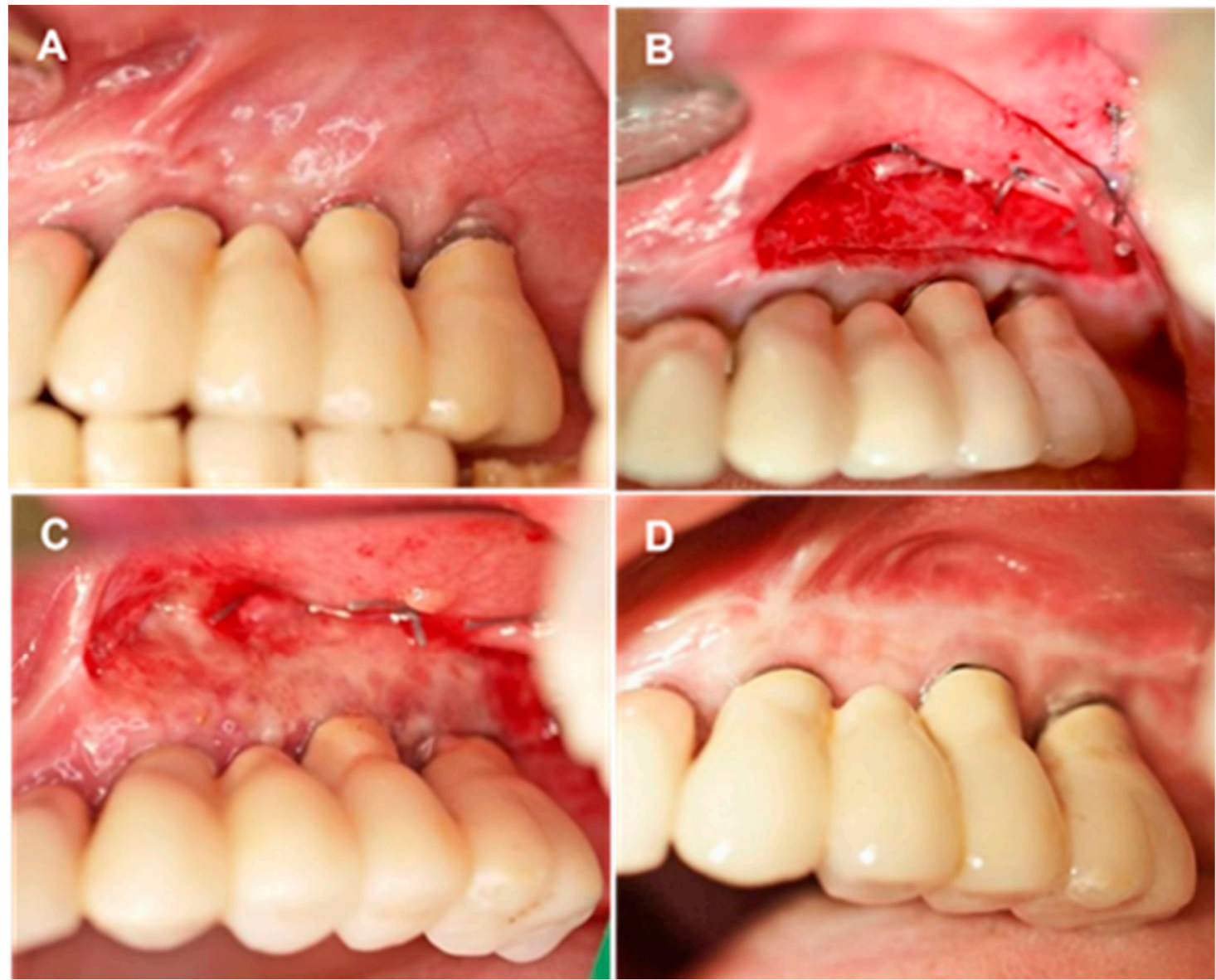

Figure 1. Overview of treatment stages. (A) Initial clinical view of area encompassing sites \#23 to \#26 after implant loading. PI-KM width $=1 \mathrm{~mm}$. (B) Intraoperative view of aCM placement and fixation on the periosteum. (C,D) Soft tissue healing in area encompassing sites \#23 to \#26, 10 days postoperatively (C) and 6 months postoperatively (D).

The following clinical parameters of target areas were assessed with a periodontal probe (PCPUNC156; Hu-Friedy, Frankfurt/M, Germany) and rounded to the nearest half millimeter perioperatively (T0) and/or 6 months after surgery (T1): width of aCM used (T0); PI-KM width from the buccal margin to the mucogingival junction (T0, T1); and bleeding on probing (BOP) at the buccal site of the peri-implant pocket (T0, T1).

\subsection{Postoperative Care}

Patients were instructed on how to brush around the grafted site with a soft toothbrush and told to rinse with only water, using no chlorhexidine or any other mouth solution, during the healing period. They were given a prescription for an anti-inflammatory (ibuprofen, $600 \mathrm{mg}$ ) and given instructions on its as-needed use for pain and swelling. The non-resorbable sutures were removed 10 days after the surgical procedure (Figure 1C). Patients were scheduled for oral hygiene maintenance, including weekly supragingival cleaning and polishing for the first five postoperative weeks, and then enrolled in supportive periodontal care (Figure 1D).

\subsection{Data Analysis}

Demographic variables were reported at the patient level (one measurement per patient), and implant variables at the implant level. Continuous variables were reported as means with standard deviations (SDs) and ranges; categorical variables were reported as numbers and percentages. The Wilcoxon matched-pairs test was used to evaluate changes in PI-KM from T0 to T1, as well as to evaluate the percentage change. Descriptive statistics 
of aCM shrinkage were recorded on metric (Equation (1)) and percentage (Equation (2)) scales as follows:

$$
\begin{aligned}
& \text { aCM shrinkage }(\mathrm{mm})=(\text { PI-KM T0 + aCM T0 })-\text { PI-KM T1 } \\
& \text { aCM shrinkage }(\%)=\text { aCM shrinkage }(\mathrm{mm}) / \mathrm{aCM} \text { T0 } \times 100
\end{aligned}
$$

Additional analyses examined how shrinkage of aCM (in $\mathrm{mm}$ ) and change in PI-KM (in $\mathrm{mm}$ ) varied between patient subgroups, such as by gender or arch). The Mann-Whitney test was used for these analyses. The cut-off for statistical significance was $p \leq 0.05$ in all cases. Statistical analyses were conducted in Stata software (v. 15.1; StataCorp LLC, College Station, TX).

\section{Results}

Demographic characteristics of the patient sample and their implant locations are reported in Table 1. Briefly, the patients' ages spanned a 29 year range, and there were similar numbers of men and women. Two-thirds of implants were placed in a posterior area, and almost two-thirds in the maxillary arch.

Table 1. Patient demographics and implant sites (mean \pm standard deviation, range, or $\mathrm{N}(\%)$.

\begin{tabular}{cccc}
\hline Measurement Level & Variable & Category & Summary \\
\hline Patients $(n=13)$ & Age & - & $53.4 \pm 8.3(39,68)$ \\
& Gender & Female & $7(54 \%)$ \\
Implants $(n=27)$ & Area & Male & $6(46 \%)$ \\
& & Posterior & $18(67 \%)$ \\
& Arch & Anterior & $9(33 \%)$ \\
& & Maxilla & $17(63 \%)$ \\
& & Mandible & $10(37 \%)$ \\
\hline
\end{tabular}

The results of study outcome variables, including changes from $\mathrm{T} 0$ to $\mathrm{T} 1$ and associated $\mathrm{p}$ values, are reported in Tables 2-4. Analyses were performed to summarize the outcomes and to examine changes in outcomes from T0 to T1. The results for the width of PI-KM are summarized in Table 2. Across 27 implants, the width of PI-KM increased from T0 $(1.1 \pm 0.3 \mathrm{~mm})$ to $\mathrm{T} 1(6.5 \pm 0.9 \mathrm{~mm})$. This difference $(5.4 \mathrm{~mm}$ on average, or $533 \%$ change) was statistically significant $(p<0.001$; Table 2$)$.

\begin{tabular}{|c|c|c|c|c|}
\hline Variable & Timepoint-Statistic & $n$ & Summary & $p$-Value \\
\hline \multirow[t]{4}{*}{ Width PI-KM (mm) } & Time $0-$ Mean \pm SD & 27 & $1.1 \pm 0.3$ & \\
\hline & Time $1-$ Mean \pm SD & 27 & $6.5 \pm 0.9$ & \\
\hline & Change $^{(*)}$-Mean $(95 \%$ CI) & 27 & $5.4(5.0,5.7)$ & $<0.001$ \\
\hline & $\%$ Change $^{(* *)}-$ Mean $(95 \%$ CI) & 27 & $533(450,616)$ & $<0.001$ \\
\hline
\end{tabular}

Table 2. Summary of outcomes and changes from T0 to T1 (Width PI-KM only).

$\left.{ }^{*}\right)$ Change calculated values at T1 minus value at T0. $\left({ }^{* *}\right) \%$ change calculated as values at (T1-T0)/Time $0 \times 100$.

Table 3. Group comparisons for aCM shrinkage (mm).

\begin{tabular}{ccccc}
\hline Variable & Category & $\boldsymbol{n}$ & mCM shrinkage. Mean \pm SD & $p$-Value \\
\hline Gender & Female & 13 & $3.7 \pm 1.4$ & 0.81 \\
& Male & 14 & $4.1 \pm 0.9$ & 0.57 \\
Area & Posterior & 18 & $3.9 \pm 1.1$ & \\
& Anterior & 9 & $3.9 \pm 1.3$ & 0.74 \\
Arch & Maxilla & 17 & $3.9 \pm 1.2$ & \\
& Mandible & 10 & $3.9 \pm 1.1$ & 0.84 \\
& Negative & 18 & $3.9 \pm 1.1$ & \\
\hline
\end{tabular}


Table 4. Group comparisons for change in PI-KM (mm).

\begin{tabular}{ccccc}
\hline Variable & Category & $\boldsymbol{n}$ & PI-KM change Mean \pm SD & $p$-Value \\
\hline Gender & Female & 13 & $5.5 \pm 1.0$ & 0.69 \\
& Male & 14 & $5.3 \pm 0.9$ & 0.83 \\
Area & Posterior & 18 & $5.4 \pm 0.9$ & \\
& Anterior & 9 & $5.3 \pm 1.0$ & 0.21 \\
& Maxilla & 17 & $5.5 \pm 0.9$ & \\
& Mandible & 10 & $5.1 \pm 0.9$ &
\end{tabular}

Further analyses examined whether aCM shrinkage varied between different groups. A summary of the results is displayed in Table 3 . The results suggested that there was no significant difference in shrinkage between any of the groups. Shrinkage did not vary by gender, area, arch, or BOP. The mean mCM shrinkage was $3.9 \mathrm{~mm}$. On the percentage scale, the mean value was $42 \%$.

\section{Discussion}

In this study, the postoperative healing and maintenance period were uneventful, with no complications of implant loss or severe inflammation.

Despite the substantial aCM shrinkage from T0 to T1 (mean shrinkage of $3.9 \mathrm{~mm}$ $(42 \%)$ ), significant PI-KM width augmentation was observed 6 months postoperatively (mean increase $5.4 \mathrm{~mm}$, mean percentage increase of 533\%). More specifically, no significant differences in shrinkage were found in relation to gender, area, arch, or BOP. In comparison to our results, Papi et al. observed a mean increase in the PI-KM width of $2 \mathrm{~mm}$ after the use of the aCM and Sanz et al. reported a mean $\mathrm{KM}$ width increase of $2.5 \mathrm{~mm}$ with the use of a different CM $[17,18,20]$. The shrinkage observed in our study falls within the range of reported FGG shrinkage (17-58\%), depending on smoking habit and/or tissue phenotype $[4,14-16,23]$. Sanz et al. used a CM Mucograft ${ }^{\circledR}$ as an alternative to FGG and reported a shrinkage of $67 \%$ [17]. This might be due to variations in the collagen production process, which can alter clinical outcomes [24,25].

The aCM used in this study is processed without chemical cross linking, as the antigenic cellular components are removed while preserving the structural integrity [26]. Previous histological analysis has revealed that it integrates well, with no foreign body reaction [27]. In fact, the aCM proved to be an excellent scaffold for the formation of new connective tissue [27]. In an animal model, the rough and porous collagen structure of this material was determined to serve as a scaffold for blood vessel and cell ingrowth, enabling revascularization of the matrix and integration of the aCM into the surrounding tissue with progressive complete remodeling $[28,29]$. Additionally, the FGGs and aCM had comparable result in vestibuloplasty leading to desirable PI-KM sufficiency, although the integration of FGGs (revascularization) and aCM (new tissue formation) differ biologically [30].

The results of this study are not conclusive, due mostly to the limitations associated with our small sample and lack of a control group. However, they suggest that the range of aCM shrinkage observed in this study cannot be attributed to demographic factors or restoration location. Variance in shrinkage may reflect inter-individual differences not examined in this study, such as matrix exposure in the oral cavity, nutritional factors, microbe presence or salivary components. Given the limited information available, we recommend that clinicians ensure close contact between the $\mathrm{aCM}$ and underlying periosteum, combined with secure fixation to prevent micro-movements that could destroy newly formed blood vessel networks. It would be interesting to check if the use of additional biomaterials in combination with aCM will provide enhanced regenerative effect [31].

\section{Conclusions}

Within the limitations of this study, the present clinical case series demonstrated that the PI-KM width can be increased effectively with aCM use. The avoidance of tissue 
harvesting from the palate leads to minor postoperative discomfort. Further studies with a larger number of treated test and control sites are necessary to verify these findings.

Author Contributions: G.-G.Z. performed the clinical treatment and the study design. A.A.A.-A. searched the literature and analyzed the clinical and experimental studies. M.A. and Z.P.K. performed the statistical analysis, wrote the results and the Tables. C.A.M. and B.T. contributed to writing and edited the final version of the article. All authors worked in the concept and design of this study as well as in the final review and writing of the manuscript. All authors have read and agreed to the published version of the manuscript.

Funding: No founding or sponsorship was received for this work.

Institutional Review Board Statement: In compliance with the Declaration of Helsinki (2013), patients were informed orally and in writing about the planned procedures and given at least 2 weeks for consideration. Patients had the right to withdraw consent and to interrupt treatment at any time without reprisal. For each patient, the treatment plan and informed consent were approved by the national health authorities (KZV—Association of Statuary Health Insurance Dentists, Germany), which also approved the case analyses and publication of the results (Dental Council North-Rhine; Germany; No: RA 232.20 AK-cls).

Informed Consent Statement: Written informed consent has been obtained from the patient(s) to publish this paper.

Conflicts of Interest: The authors declare no conflict of interest.

\section{References}

1. Hjalmarsson, L.; Gheisarifar, M.; Jemt, T. A systematic review of survival of single implants as presented in longitudinal studies with a follow-up of at least 10 years. Eur. J. Oral Implantol. 2016, 9 (Suppl 1), S155-S162.

2. Chrcanovic, B.R.; Kisch, J.; Albrektsson, T.; Wennerberg, A. A retrospective study on clinical and radiological outcomes of oral implants in patients followed up for a minimum of 20 years. Clin. Implant. Dent. Relat. Res. 2018, 20, 199-207. [CrossRef]

3. Zuhr, O.; Bäumer, D.; Hürzeler, M. The addition of soft tissue replacement grafts in plastic periodontal and implant surgery: Critical elements in design and execution. J. Clin. Periodontol. 2014, 41, S123-S142. [CrossRef]

4. Dorfman, H.S.; Kennedy, J.E.; Bird, W.C. Longitudinal Evaluation of Free Autogenous Gingival Grafts: A Four Year Report. J. Periodontol. 1982, 53, 349-352. [CrossRef]

5. Souza, A.B.; Tormena, M.; Matarazzo, F.; Araújo, M.G. The influence of peri-implant keratinized mucosa on brushing dis-comfort and peri-implant tissue health. Clin. Oral Implants Res. 2016, 27, 650-655. [CrossRef]

6. Thoma, D.S.; Naenni, N.; Figuero, E.; Hämmerle, C.H.F.; Schwarz, F.; Jung, R.E.; Sanz-Sánchez, I. Effects of soft tissue augmentation procedures on peri-implant health or disease: A systematic review and meta-analysis. Clin. Oral Implant. Res. 2018, 29, 32-49. [CrossRef]

7. Zigdon, H.; Machtei, E.E. The dimensions of keratinized mucosa around implants affect clinical and immunological parameters. Clin. Oral Implant. Res. 2008, 19, 387-392. [CrossRef] [PubMed]

8. Scarano, A.; Murmura, G.; Sinjiari, B.; Sollazzo, V.; Spinelli, G.; Carinci, F. Analysis and Structural Examination of Screw Loosening in Oral Implants. Int. J. Immunopathol. Pharmacol. 2011, 24, 77-81. [CrossRef] [PubMed]

9. Moraschini, V.; Luz, D.; Velloso, G.; Barboza, E. Quality assessment of systematic reviews of the significance of keratinized mucosa on implant health. Int. J. Oral Maxillofac. Surg. 2017, 46, 774-781. [CrossRef] [PubMed]

10. Chung, D.M.; Oh, T.-J.; Shotwell, J.L.; Misch, C.E.; Wang, H.-L. Significance of Keratinized Mucosa in Maintenance of Dental Implants With Different Surfaces. J. Periodontol. 2006, 77, 1410-1420. [CrossRef]

11. Orsini, M.; Orsini, G.; Benlloch, D.; Aranda, J.J.; Lázaro, P.; Sanz, M. Esthetic and Dimensional Evaluation of Free Connective Tissue Grafts in Prosthetically Treated Patients: A 1-Year Clinical Study. J. Periodontol. 2004, 75, 470-477. [CrossRef]

12. Zafiropoulos, G.-G.; John, G.; Patil, S. Use of Collagen Matrix for Augmentation of the Peri-implant Soft Tissue at the Time of Immediate Implant Placement. J. Contemp. Dent. Pr. 2017, 18, 386-391. [CrossRef] [PubMed]

13. Zafiropoulos, G.-G.; Deli, G.; Hoffmann, O.; John, G. Changes of the peri-implant soft tissue thickness after grafting with a collagen matrix. J. Indian Soc. Periodontol. 2016, 20, 441-445. [CrossRef]

14. Silva, C.O.; Ribeiro, E.D.P.; Sallum, A.W.; Tatakis, D.N. Free Gingival Grafts: Graft Shrinkage and Donor-Site Healing in Smokers and Non-Smokers. J. Periodontol. 2010, 81, 692-701. [CrossRef]

15. Chandra, R.V.; Sneha, K.; Anvesha, P. Free gingival grafts vs mucosal excision in increasing the amount of keratinized mucosa during exposure of submerged orthodontic implants: A comparative, split-mouth study. Quintessence Int. 2020, 51, 2-10.

16. Parvini, P.; Galarraga-Vinueza, M.E.; Obreja, K.; Magini, R.D.S.; Sader, R.; Schwarz, F. Prospective study assessing threedimensional changes of mucosal healing following soft tissue augmentation using free gingival grafts. J. Periodontol. 2020, 92, 400-408. [CrossRef] [PubMed] 
17. Sanz, M.; Lorenzo, R.; Aranda, J.J.; Martin, C.; Orsini, M. Clinical evaluation of a new collagen matrix (Mucograft prototype) to enhance the width of keratinized tissue in patients with fixed prosthetic restorations: A randomized prospective clinical trial. $J$. Clin. Periodontol. 2009, 36, 868-876. [CrossRef]

18. Papi, P.; Pompa, G. The Use of a Novel Porcine Derived Acellular Dermal Matrix (Mucoderm) in Peri-Implant Soft Tissue Augmentation: Preliminary Results of a Prospective Pilot Cohort Study. BioMed Res. Int. 2018, 2018, 1-9. [CrossRef]

19. Puisys, A.; Zukauskas, S.; Kubilius, R.; Barbeck, M.; Razukevičius, D.; Linkevičiene, L.; Linkevičius, T. Clinical and histologic evaluations of porcine-derived collagen matrix membrane used for vertical soft tissue augmentation: A case series. Int. J. Periodontics Restor. Dent. 2019, 39, 341-347. [CrossRef]

20. Papi, P.; Pranno, N.; Di Murro, B.; Pompa, G. Early implant placement and peri-implant augmentation with a porcine-derived acellular dermal matrix and synthetic bone in the aesthetic area: A 2-year follow-up prospective cohort study. Int. J. Oral Maxillofac. Surg. 2021, 50, 258-266. [CrossRef]

21. Beretta, M.; Maiorana, C.; Manfredini, M.; Ferrario, S.; Poli, P.P. Buccal Peri-Implant Soft Tissue Augmentation by Means of a Porcine Collagen Matrix: A Proof of Concept Technical Note. Materials 2020, 14, 93. [CrossRef] [PubMed]

22. Stefanini, M.; Rendon, A.; Zucchelli, G. Porcine-Derived Acellular Dermal Matrix for Buccal Soft Tissue Augmentation at Single Implant Sites: A 1-Year Follow-up Case Series. Int. J. Periodontics Restor. Dent. 2020, 40, 121-128. [CrossRef]

23. Karakış Akcan, S.; Güler, B.; Hatipoğlu, H. The effect of different gingival phenotypes on dimensional stability of free gingival graft: A comparative 6-month clinical study. J. Periodontol. 2019, 90, 709-717. [CrossRef]

24. Meyer, M. Processing of collagen based biomaterials and the resulting materials properties. Biomed. Eng. Online 2019, 18, 1-74. [CrossRef]

25. Patino, M.G.; Neiders, M.E.; Andreana, S.; Noble, B.; Cohen, R.E. Collagen as an Implantable Material in Medicine and Dentistry. J. Oral Implant. 2002, 28, 220-225. [CrossRef]

26. Ghanaati, S.; Schlee, M.; Webber, M.; Willershausen, I.; Barbeck, M.; Balic, E.; Görlach, C.; I Stupp, S.; A Sader, R.; Kirkpatrick, C.J. Evaluation of the tissue reaction to a new bilayered collagen matrix in vivo and its translation to the clinic. Biomed. Mater. 2011, 6, 015010. [CrossRef] [PubMed]

27. Rothamel, D.; Benner, M.; Fienitz, T.; Happe, A.; Kreppel, M.; Nickenig, H.-J.; E Zöller, J. Biodegradation pattern and tissue integration of native and cross-linked porcine collagen soft tissue augmentation matrices-An experimental study in the rat. Head Face Med. 2014, 10, 10. [CrossRef]

28. Preidl, R.H.; Reichert, S.; Coronel, T.V.; Kesting, M.; Wehrhan, F. and Schmitt, C.M. Free Gingival Graft and Collagen Matrix Revascularization in an Enoral Open Wound Situation. J. Oral Maxillofac. Surg. 2021, 79, 1027-1037. [CrossRef] [PubMed]

29. Barbeck, M.; Lorenz, J.; Kubesch, A.; Böhm, N.; Booms, P.; Choukroun, J.; Sader, R.; Kirkpatrick, C.J.; Ghanaati, S. Porcine der-mis-derived collagen membranes induce implantation bed vascularization via multinucleated giant cells: A physiological reaction? J. Oral Implantol. 2015, 41, 238-251. [CrossRef] [PubMed]

30. Schmitt, C.M.; Tudor, C.; Kiener, K.; Wehrhan, F.; Schmitt, J.; Eitner, S.; Agaimy, A.; Schlegel, K.A. Vestibuloplasty: Porcine Collagen Matrix Versus Free Gingival Graft: A Clinical and Histologic Study. J. Periodontol. 2013, 84, 914-923. [CrossRef]

31. Rexhepi, I.; Paolantonio, M.; Romano, L.; Serroni, M.; Santamaria, P.; Secondi, L.; Paolantonio, G.; Sinjari, B.; De Ninis, P.; Femminella, B. Efficacy of inorganic bovine bone combined with leukocyte and platelet-rich fibrin or collagen membranes for treating unfavorable periodontal infrabony defects: Randomized non-inferiority trial. J. Periodontol. 2021. [CrossRef] [PubMed] 